\title{
INDIGENOUS IDENTITIES AND THE POLITICS OF
}

\section{AUTHENTICITY}

\section{Michelle Harris, Bronwyn Carlson \& Evan Poata-Smith}

The very question of Indigenous authenticity, as Jeffrey Sissons reminds us, "...has deep roots within colonial racism" $(2005,43)$. Racialisation and the practice of creating and imbuing racial categories with seemingly impermeable boundaries and indestructible meanings has, after all, underpinned a range of colonial practices from the systematic alienation of Indigenous land and resources to child abduction. Regimes of biological and cultural authenticity continue to shape state policies and practices that regulate the everyday lives of Indigenous people around the world. Indeed, in some contexts, expectations of Indigenous cultural purity or environmental naturalness exist alongside the imposition of varying degrees of blood quantum as criteria for citizenship, political recognition and access to resources and services.

Failure to express Indigenous identities in these terms often undermines the credibility of those individuals and groups who claim Indigeneity but resist such institutionally sanctioned identity categories. Although there are real material and non-material rewards associated with adopting Western stereotypes of Indigeneity that are recognised by institutions of the state and wider public, this is a double edge sword. As Sissons has noted, $(2005,39)$ "The operation of oppressive authenticity has been integral to the foundation of all settler nations and it continues to haunt the formation and implementation of their cultural politics. Included in the excluded middles of many post-settler states today are millions of Indigenous 
people variously described as 'half-castes', 'mixed-blood', 'urbanized', non-traditional' and 'westernized'-usually the majority of their Indigenous citizens." $(2005,39)$. In this way, a significant number of Indigenous people find themselves marginalised and dismissed as contaminated, impure and inauthentic.

It is not our goal in this volume to interrogate who legitimately has claim to Indigenous identity, how one should define "Indigenousness," or to document the identity making process among Indigenous peoples. Rather, it is our intent to explore what it means to claim Indigenous identity in contemporary times-whether one can meet state or community standards of "legitimate" Indigenous status. We also explore some of the ways individuals inhabit, negotiate and challenge existing definitions of "Indigenous identity," and how many others are creating new ways of "being" Indigenous.

\section{Identities: Relational and Contextual}

The concept of 'identity' has been deployed in such a myriad of different ways in the social and behavioral sciences, there has been a lack of consistency and clarity in its definition and application (Hall 1996). To some extent the wide variety of conceptualisations and definitions of identity simply reflect the concerns of different disciplinary paradigms with their own distinctive theoretical and empirical traditions. Conceptually, it is possible to make the distinction between notions of 'personal identity' and 'social identity' (Burke 2004). 'Personal identities' on the one hand are the selfdesignations and self-attributions that an individual enacts or asserts during the course of social interaction with others, and are essentially the meanings the individual attributes to the 'self (Snow and Anderson 1987). The concept of 'social identities', on the other hand, provides a conceptual link between the individual's representation of 
'self and the social structures and groups in which the 'self is embedded and ultimately constituted (Coupland 2007).

The concept of identity is both a relational and contextual construct. It is relational in the sense that it is not possible to hold a social identity all alone. All social identities are reflexively produced in interaction with others. The consequence of this interaction has been the production of 'representations' of other individuals and groups in terms of real or attributed differences, and of course for those that construct these representations, the establishment of criteria by which they represent themselves. While group identities must always be defined in relation to non-members of the group, the criteria for differentiation are contested and variable within groups themselves (Eriksen 2002). Indeed, there is seldom consensus about the norms, boundaries and world views that constitute the essence of a collective identity.

Identities are contextual in the sense that they are constituted differently in different historical and cultural contexts. In this way, identity is "...a socially constructed, variable definition of self or other, whose existence and meaning is continuously negotiated, revised and revitalized" (Nagel 1993, 2). The assumption that an individual possesses a unique core or underlying essence-the 'real me'-an authentic identity that is coherent and remains more or less the same throughout life, is a characteristic of essentialist arguments about identity. Rather than represent the "self" as a unified, fixed and unchanging construct, the chapters in this volume show how our notions of "self" are the product of a range of shifting and diverse social and cultural categories and identifications that are rarely stable. While obviously a repository of distinct individual and collective experiences, identities have been increasingly conceptualised as dynamic and shifting and as a process of becoming rather than being. 
Moreover, because our identities are formed and constituted in interaction with other people, they are fluid and evolve over the course of our lives. As Stuart Hall has argued, identity should not be theorised in terms of a "...stable core of the self unfolding from beginning to end through all the vicissitudes of history without change" (Hall 1996, 3).

More recent approaches have tended to treat identities as discursive resources. To have an identity, as Stevenson notes, is “...to be able to tell a story about the self and related communities. An identity is like a narrative that has to be constantly retold and reformulated in the light of new circumstances" (Stevenson 2006, 278). And while this discursive element to identity defies fixedness, and by definition is emergent, it does not imparts agentic power. Discourses are inert and by definition cannot possess agency and the capacity to act in the world. Of course, as Bob Carter notes, “...there are ways in which discourses can be said to condition and constrain what actors may say and do, but they cannot 'mobilize' or 'signal' or 'set boundaries' or 'prevail over'. All of these elements require intentionality and reflexivity-and, of course, discourses possess neither of these qualities" (Carter 2000, 48). It is important to emphasise, therefore, that it is not discourses of identity that impose particular interpretations of authenticity on individuals and groups, but social actors. The tensions between actors, and the particular discourses they articulate, are concretely negotiated in particular historical settings.

This last point is one of the conceptual cornerstones of this volumehuman actors deliberately and intentionally act out their identities in ever-changing ways as a consequence of the social relations and settings in which they find themselves. Identity, we contend, is a product of both agency and structure. While institutionalised forms of social conduct place limits on our autonomy, social life is both 
enabling and constraining. Social actors are also creative agents who attempt to construct their own sense of social identity and may challenge (or not) the prevailing social constraints and social structures. Nevertheless, social actors do not do this in circumstances of their own choosing. As Peter Berger has argued, social identities are "socially bestowed, socially sustained and socially transformed" (Berger 1963, 98).

\section{Emergent Indigenous Identities}

Indigenous identities are reflexively produced and depend as much upon the recognition of others as they do on the self-designations and self-attributions we assert during the course of social interaction with others. Rather than constituting a unified, fixed and unchanging construct, Indigenous identities are, therefore, always in flux; they are a response to shifting and diverse social and cultural categories and identifications that are rarely stable. In this sense, Indigenous identities are emergent; a process of becoming rather than being.

Indigenous identities not only develop from the constant ebb and flow of interactions between individuals and others, those interactions are frequently sites of contestation. Individuals laying claim to particular identities may find that others challenge those claims. The evaluation of others may be accepted or rejected by the individual, but it is in this context that claims and counter-claims about indigenous identities emerge. In this sense, the negotiation and renegotiation of indigenous identities involves claiming and resisting identities from within a set of prevailing discourses about the authenticity of particular indigenous categories. The social actors that articulate these discourses are themselves, of course, embedded in unequal sets of social, economic and political relations. As a result, these narratives about who should count as indigenous have conflicting political implications for different groups of indigenous people in the present 
especially given the increasingly diverse circumstances in which indigenous people now find themselves.

Indeed, colonial processes and practices have fundamentally transformed (and in some cases severed) the relationships that indigenous people have to place and to kin in a variety of ways. Some claims to indigenous identity align closely with the notions of biological and/or cultural authenticity that are so powerfully entrenched in institutional practices and the public consciousness. There are real material and non-material rewards for those and who can perform this indigenous 'otherness' in visible ways. In other cases, colonialism has restructured indigenous communities to such an extent that many individuals only become aware of their indigeneity later in their lives. Overtime, many have sought to re-establish those social and cultural connections. Identifying as indigenous, however, is not a straight-forward process and requires navigating particular narratives of belonging and discourses about what constitutes an 'authentic' or 'traditional' indigenous identity. If one cannot "be" in the right way, does one get to "be"? It is also important to recognise that many indigenous people, finding themselves caught once again in a binary not of their own making, continue to vigorously resist institutionally sanctioned identity categories viewing the preoccupation with notions of indigenous authenticity as racism and primitivism in disguise.

Identities, whether personal or collective, are inherently political. The politics of identity can involve the construction, reconstruction or disruption of notions about what it means to claim particular identities, or the creation or recreation of meanings attached to themespecially if these efforts are attempts to shift power relations within or between groups. Often, it is thought that the social, economic or resource stakes are much higher when out-groups (indigenous and 
non-indigenous) interact, but differential access to power occurs within and among indigenous groups.

The chapters in this volume explore some of the critical issues that impact on our understandings of indigeneity. They take the position that while identities are not fixed and immutable, nor can they be simply dismissed as an ideological fiction; they have real-life meaning and consequence. Indeed, it is clear that identities constitute significant modes through which people continue to experience, understand and explain the world around them. Therefore, identities, we believe, while socially and historically situated, are open to individual interpretation as to their usefulness and meaning at a particular point in time, and, as such, the political implications of a particular identity are not fixed or generalisable. Having said this, we do not mean to imply that we think indigenous identity is a kind of essence. Rather, we see it as a social fact, a knowledge system, a social location and an important factor in social relations-social relations that are ultimately political in nature!

\section{The Working Group on Emergent Indigenous Identities}

In 2010 a group of international scholars gathered at Northern Arizona University for the first working group discussing the topic of 'emergent indigenous identities'. The majority of members of the working group identified as indigenous to various geographical locations, identifying as Aboriginal, Torres Strait Islander, Maori, Mexican, Native American and Inuit. As culturally appropriate to many of the indigenous participants, presentations followed after recognition of ancestors, kin and country. These cultural acknowledgements included various languages (including English) and at times artifacts and images. After the formal proceedings were done with, discussion arose about the performitivity of indigeneity. One member of the group spoke about the anxiety she felt giving her 
presentation, as she was not wearing a necklace, which is specific to her people/culture. She commented that the necklace when worn signified to others her indigeneity and membership of a specific cultural group. The indigenous members recalled various experiences where they felt the need to perform or overly perform their indigeneity to ensure recognition of their identity.

The focus of the working group was guided by the following questions: Are emergent identities-new constructed identities that emerge as a function of historical moment, place and social forces"legitimately" available to groups such as those who claim Indigenous/Aboriginal/First Nation status? If so, what forces help to forge these identities? What are the ways in which these identities are performed throughout the world among indigenous groups? What are some of the challenges (both from outside and within groups) that indigenous individuals face as they negotiate the fine line between "authentic" cultural expression and new emergent identities? How do claims to multiple racial or ethnic identities affect one's emergent indigenous identity? The 'working group' is unique in that it is an international, multi disciplinary cohort coming together to "open up" the conversation about emergent indigenous identities in myriad ways so that we can begin to understand both the breadth and depth of this important topic.

This edited volume is the result of the collaboration of the participants of the working group.

\section{References}

Berger, P. (1963), Invitation to Sociology. A Humanistic Perspective. New York: Anchor Books.

Burke, P.J. (2004), 'Identities and Social Structure: The 2003 CooleyMead Award Address', Social Psychology Quarterly 67: 5-15. 
Carter, B. (2000), Realism and Racism: Concepts of Race in Sociological Research, London: Routledge.

Coupland, C. (2007), 'Identity: the Management of Meaning' in Ritzer, George (ed.), Blackwell Encyclopedia of Sociology, Oxford: Blackwell Publishing.

Eriksen, T.H. (2002) Ethnicity and Nationalism (2 ${ }^{\text {nd }}$ ed.), London: Pluto Press.

Hall, S. (1996), 'Introduction: Who Needs Identity?' in Hall, S. and du Gay P. (eds.), Questions of Cultural Identity, London: Sage Publications.

Nagel, J. (1993), 'Constructing ethnicity: creating and recreating ethnic identity and culture', in Yetman, N. (ed.), Majority and Minority: The Dynamics of Race and Ethnicity in American Life, 6th ed., Boston, MA: Allyn and Bacon.

Sissons, J. (2005), First Peoples: Indigenous Cultures and Their Futures, London: Reaktion Books.

Snow, D.A. \& Anderson, L. (1987) 'Identity Work Among the Homeless: The Verbal Construction and Avowal of Personal Identities', The American Journal of Sociology, Vol. 92, No. 6. (May, 1987), pp. 1336-1371.

Stevenson, N. (2006), 'Identity', in Turner, B.S. (ed)., Cambridge Dictionary of Sociology, Cambridge: Cambridge University Press. 